\title{
"De las obras públicas del pueblo": Investigación interdisciplinar sobre equipamientos e infraestructuras municipales en el Quinientos castellano
}

\author{
Luis J. GoRdo Peláez \\ The University of Texas at Austin, Teresa Lozano Long Institute of Latin American Studies
}

\begin{abstract}
RESUMEN
El siglo XVI fue particularmente relevante para el tema de los equipamientos e infraestructuras municipales en la Corona de Castilla. En 1922 Vicente Lampérez y Romea acometía la proeza de estudiar el inmenso repertorio de obras, incluidas las edificaciones públicas, que configuran La arquitectura civil española de los siglos I al XVIII. Tras los pasos y el legado de tan eminente maestro, iniciamos una investigación doctoral de carácter interdisciplinar destinada a sistematizar y actualizar un capítulo concreto de tan extenso repertorio arquitectónico, las obras municipales del Renacimiento castellano. Con motivo de la celebración del II Encuentro Complutense de "Jóvenes Investigadores de Historia del Arte" tuvimos la oportunidad de exponer las principales cuestiones abordadas en dicho trabajo, los objetivos planteados y la metodología empleada. Temas de los que aquí ofrecemos una breve síntesis.
\end{abstract}

Palabras clave: Gobierno municipal; arquitectura pública; Castilla.

\section{"On the city's public Works": Interdisciplinary research on civic architecture in Sixteenth-century Castile}

\begin{abstract}
The sixteenth century was particularly relevant to the topic of civic architecture in the Crown of Castile. In 1922, Vicente Lampérez y Romea studied the vast repertoire of works, including public buildings, which make up La arquitectura civil española de los siglos I al XVIII. Following the steps and the legacy of this eminent architect, we began an interdisciplinary doctoral research intended to systematize and update a particular chapter of that extensive architectural repertoire: the municipal architecture in Castilian Renaissance. On the occasion of the II Encuentro Complutense de "Jóvenes Investigadores de Historia del Arte", we had the opportunity to outline the main topics addressed in this research, the objectives and methodology. Here is a brief synopsis of these ideas.
\end{abstract}

Keywords: Municipal government; civic architecture; Castile.

En 1742, siguiendo los planteamientos formulados siglo y medio antes por el célebre jurista Jerónimo Castillo de Bovadilla, Lorenzo Santayana Bustillo enumeraba nuevamente cuáles eran aquellas fábricas y "obras pvblicas del pueblo" que 
competía al corregidor promover y a la ciudad y gobierno municipal costear ${ }^{1}$. Entre estos equipamientos e infraestructuras, señalaba, "ha de haver en el Pueblo Casa de Ayuntamiento, donde se junten los que le goviernen a tratar del Gobierno de la Republica. Es preciso tengan tambien carcel segura para los delinquentes. No menos es necessario el adorno de las plazas; la seguridad de los muros es igualmente precisa; la fabrica de puentes, y fuentes es en muchos inevitable. En todos es forzosa la limpieza de las calles, y que los caminos, y transitos esten compuestos; que se derriben los edificios que amenazan ruina; y en algunos, que son de numerosa población, suele haver casas para la venta de carnes, pescados, y otros abastos"2.

El proceso de construcción de obras y equipamientos municipales fue una tarea colectiva en la que participaron simultáneamente todos los territorios castellanos, conforme a la transformación que experimentan las ciudades del Humanismo desde fines del siglo XV. En esta febril campaña edilicia se implicaron, en la medida de lo posible, desde grandes municipios como Sevilla hasta reducidas villas como Hornachos, en Badajoz. Dicha simultaneidad se muestra en diversas obras públicas ejecutadas en aquellas fechas. Por ejemplo, a la par que el concejo municipal de León costeaba la fábrica de una nueva y más capaz casa de carnicerías o el regimiento cacereño de Trujillo acordaba erigir los Portales del Pan en la plaza Mayor y renovar la sala de cabildos de su consistorio; por su parte, el Asistente de Sevilla impulsaba la remodelación de las puertas de entrada a la ciudad, el municipio conquense de San Clemente se dotaba de una magnífica casa consistorial, y los regidores de Toledo decidían acondicionar la cárcel real y ampliar sus dependencias con la construcción de una cámara para audiencia de causas criminales.

La unificación y cohesión del territorio castellano a fines del siglo $\mathrm{XV}$, con la llegada al trono de los Reyes Católicos, el crecimiento demográfico, cierta prosperidad económica y el renacimiento de la cultura urbana, son algunos de los factores que condicionaron el proceso iniciado entonces por los gobiernos municipales para dotar a las ciudades de equipamientos destinados a subsanar sus carencias en cuestiones como la red de comunicaciones y accesos al municipio, el asiento de los concejos en casas consistoriales, la creación de recintos carcelarios y tribunales de justicia, la provisión de mantenimientos a la población, la red de abastecimiento de agua, la ordenación del sistema viario, o las mejoras en la higiene urbana y salubridad pública.

1 CASTILlo DE BOVADILla, Jerónimo, Politica para Corregidores y señores de vassallos, en tiempo de paz y de guerra. Y para juezes eclesiásticos y seglares y de Sacas, Aduanas, y de Residencias, y sus Oficiales: y para Regidores, y Abogados, y del valor de los Corregimientos, y Goviernos Realengos, y de las Ordenes, Madrid, Instituto de Estudios de Administración Local, 1978 (Amberes, 1704), vol. II, lib. III, cap. $\mathrm{V}$, pp. 75-76.

2 SANTAYANA BUSTILlO, Lorenzo, Govierno político de los pueblos de España, y el Corregidor, Alcalde y Juez en ellos, Zaragoza, Imprenta de Francisco Moreno, 1742, ff. 84-86 y 117-118. 
Este extenso repertorio de equipamientos e infraestructuras municipales requería, a nuestro juicio, de una actualizada sistematización tomando como punto de partida la precursora obra de Vicente Lampérez y Romea, La arquitectura civil española de los siglos I al XVIII, publicada en 1922. Referente incuestionable para generaciones de historiadores, el trabajo de Lampérez, cuya introducción enunciaba ya la necesidad de elaborar un "cuadro de conjunto de la Arquitectura civil" en España, orientó desde el inicio nuestra investigación doctoral sobre las mencionadas obras públicas del Quinientos.

Desde el punto de vista historiográfico, los equipamientos municipales habían recibido desde entonces un tratamiento muy desigual. Aunque no faltaban los estudios e investigaciones sobre esta materia, se carecía de un trabajo que, en la línea trazada por Lampérez, reuniera en su conjunto las obras públicas costeadas por los concejos de los municipios castellanos. Las publicaciones de las últimas décadas se habían orientado principalmente hacia dos vertientes. Por un lado, los estudios centrados en una ciudad o región concreta. De otro, aquellos que se habían volcado en el análisis de ciertas edificaciones más singulares, particularmente significativas en su día, bien por la participación de cualificados maestros, por la suntuosidad y envergadura de sus fábricas, o bien por la influencia que ejercieron como modelo de aquella tipología arquitectónica.

A pesar de la validez de muchos de estos trabajos previos, para nosotros se planteaba la necesidad de ofrecer una revisión del tema siguiendo el legado de Lampérez, a modo de elaborada síntesis que no se centrara sólo en un municipio o provincia concreta o en una única tipología de edificios, sino que analizara este amplio campo de los equipamientos y obras municipales como una experiencia conjunta y de enorme éxito en toda la Corona de Castilla durante el siglo XVI.

Nuestro objetivo de actualizar y precisar cuestiones sobre equipamientos municipales, algunas tan sólo ligeramente enunciadas por el mencionado historiador, fue planteado desde el inicio con un carácter interdisciplinar, en el que concurrieran a la par aspectos sociológicos, históricos, legislativos, y económicos, demás de los necesariamente artísticos. Conforme a aquella visión global que queríamos transmitir, este era un tema que requería también un tratamiento más amplio en el que tuvieran cabida tanto las aportaciones de la historiografía artística tras la obra de Lampérez, como otros estudios y fuentes documentales de diversas disciplinas que resultaban imprescindibles para completar nuestra propuesta de recorrido por estos equipamientos municipales.

Entre el extenso conjunto de fuentes impresas al que recurrimos para el desarrollo de la investigación fue prioritaria la consulta de textos legislativos, en particular de recopilaciones de leyes y ordenanzas municipales, de singular relevancia en la política de obras e infraestructuras públicas y fuente esencial para el estudio del gobierno de las ciudades castellanas en la Edad Moderna. El trabajo se completó también con el estudio y análisis de otras colecciones documentales, en particular 
libros de ordenamientos, cédulas, provisiones y pragmáticas reales; así como tratados y discursos de juristas y arbitristas de la Edad Moderna. Los relatos de viajeros; los textos de literatos y humanistas coetáneos; las respuestas a las Relaciones topográficas ordenadas por Felipe II; las guías y catálogos de monumentos; los tratados de arquitectura e ingeniería; y, sobre todo, el género de los laudes urbis y la historiografía local, se convirtieron también en fuentes imprescindibles para el desarrollo de la investigación, constituyendo un testimonio sólido para muchos de los planteamientos argumentados en nuestro trabajo.

En este sentido, el estudio e incorporación de todas estas fuentes mencionadas nos ha permitido elaborar el discurso contextualizado de cada uno de los equipamientos municipales, en cierta manera, conforme al "conocimiento de las causas y de los efectos; del aspecto social y de la forma arquitectónica consiguiente", pasos que ya Lampérez intuía como necesarios para la composición de una eventual Historia de la Arquitectura Civil Española ${ }^{3}$. Más allá de una simple catalogación estilística de edificaciones, el desarrollo de la investigación nos ha permitido exponer el conjunto de equipamientos e infraestructuras públicas reseñadas a modo de extenso repertorio de programas constructivos que daban respuesta a unos condicionantes concretos de carácter sociológico, económico e histórico. Entre los diversos aspectos que hemos concretado para un mejor conocimiento de esta arquitectura en toda la Corona de Castilla cabe citar, el contexto legislativo y social al que daban respuesta estos equipamientos públicos, la necesidad y utilidad de estas construcciones, el por qué de su particular emplazamiento en el núcleo urbano, cuáles eran las diversas dependencias y aposentos que conformaban el interior de algunas fábricas, las razones de su traza y forma, la concepción de sus fachadas o "delanteras", la manera de costear su edificación, o las connotaciones de carácter emblemático que encerraban los recursos decorativos empleados en aquellas obras y conjuntos edilicios municipales.

Partiendo del sistema de comunicaciones, enumeramos a continuación aquellas edificaciones que conformaban este singular repertorio de equipamientos municipales, objeto de nuestra investigación interdisciplinar. A comienzos de la Edad Moderna, para humanistas, tratadistas y maestros en arquitectura no era desconocido el magnífico precedente de la Antigüedad, tanto por la extensión de sus actuaciones como por la envergadura de algunas de sus obras. Parte de esa completa red de infraestructuras viarias que los romanos habían trazado en la Península había perdurado, a pesar de las alteraciones medievales, en el singular legado de los puentes. Durante el siglo XVI, la necesidad de mejorar las comunicaciones y los accesos a los municipios, motivó el reparo de estas antiguas fábricas y la edificación de nuevos pasos, a la par que se adecentaban y mantenían practicables caminos y calzadas

LAMPÉREZ Y ROMEA, Vicente, La arquitectura civil española de los siglos I al XVIII, Madrid, Editorial Saturnino Calleja, 1992, vol. I, p. 13. 
que demás de facilitar el tránsito entre los diferentes reinos y regiones peninsulares, favorecían el tráfico comercial y el desarrollo económico; y permitían garantizar el abastecimiento de la población. Al definir el término "calçada", el lexicógrafo Sebastián de Covarrubias señalaba que era "obra necessaria para poder tener trato y comercio en todos tiempos vnos lugares con otros"4.

Más singular, si cabe, fue la intervención de los concejos sobre los recintos amurallados y accesos que encerraban los municipios castellanos. Distinción y emblema, unos y otros, de un mundo urbano que hacía de aquéllos, los muros, custodios de sus intereses económicos y de su salubridad pública; y de éstos, las puertas y arcos, ornato urbano, e imagen de conmemoración triunfal. Así lo advirtió Jouvin al contemplar la puerta de Santa María a su paso por la ciudad de Burgos en 1672 (fig. 1). Relataba este viajero francés como, frente al puente homónimo, "se ve allí la puerta de la ciudad, por donde se sale para pasarlo, que se parece a un arco de triunfo, a causa de varias figuras, entre otras la de la Virgen que está acompañada de varios ángeles"s.

A fines del siglo XV asistimos también al protagonismo creciente que adquieren los concejos municipales. A éstos correspondía, entre otras, la función de compilar la legislación de la ciudad y elaborar nuevas ordenanzas que regularan, entre otros temas, el gobierno y tareas de los oficiales municipales, el abasto de la población, y el ornato urbano. Con el propósito de consignar un espacio que acogiera las reuniones de estos concejos, un lugar apropiado y "decente para la representación de la nobleza del pueblo", según señalaba el jurista Castillo de Bovadilla, en 1480 los Reyes Católicos promulgaban el célebre ordenamiento que obligaba a disponer, en todos los municipios castellanos, de "casas grandes y bien hechas en que hagan sus Ayuntamientos y Concejos, en que se ayunten las Jus-

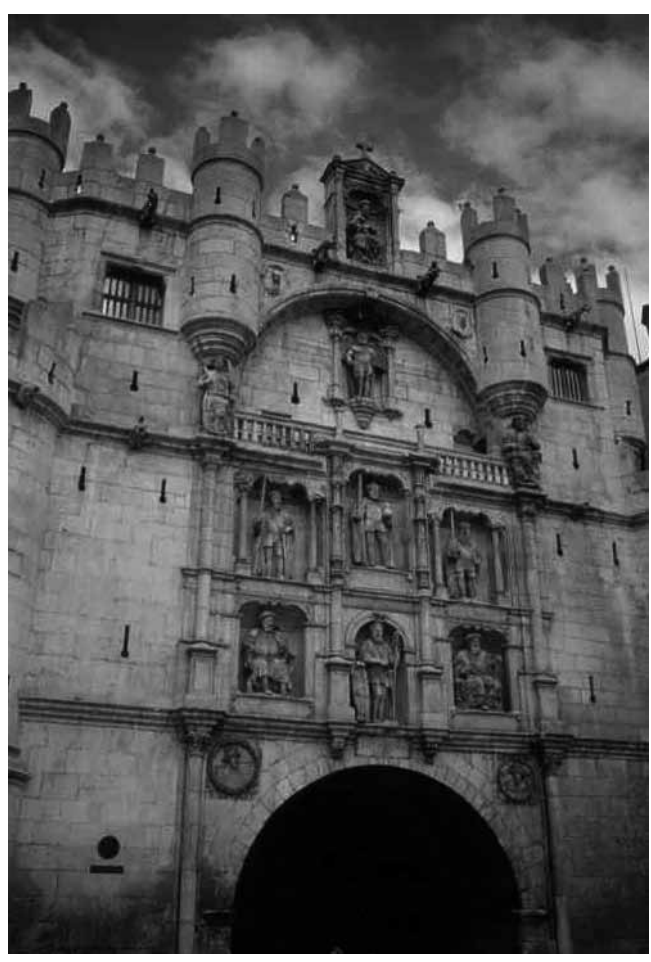

Fig. 1. Puerta de Santa María, Burgos, segundo tercio del siglo XVI, fachada.

4 COVARRUBIAS OROZCO, Sebastián, Tesoro de la Lengua castellana o española, Madrid, Luis Sánchez, 1611, f. 120r.

5 JOUVIN, Alfred, "El viaje de España y Portugal”, en GARCÍA MERCADAL, José, Viajes de extranjeros por España y Portugal, vol. II, Madrid, Aguilar, 1959, p. 779. 
ticias, y Regidores, y Oficiales a entender en las cosas cumplideras a la república que han de governar". Su carácter emblemático, como edificio que acogía a "los que gouiernan lo temporal", implicaba además emplazar estas construcciones "en medio de la ciudad, porque hacia todas partes suelen morar los regidores della", subrayando el papel preponderante de los concejos y sus nuevas edificaciones sobre la vida y el urbanismo de las ciudades ${ }^{7}$. Adornadas y embellecidas conforme a la dignidad que correspondía a sus ocupantes y a la propia grandeza del municipio, las casas consistoriales se convirtieron en motivo de orgullo cívico y emblema de prestigio y modernidad (fig. 2).

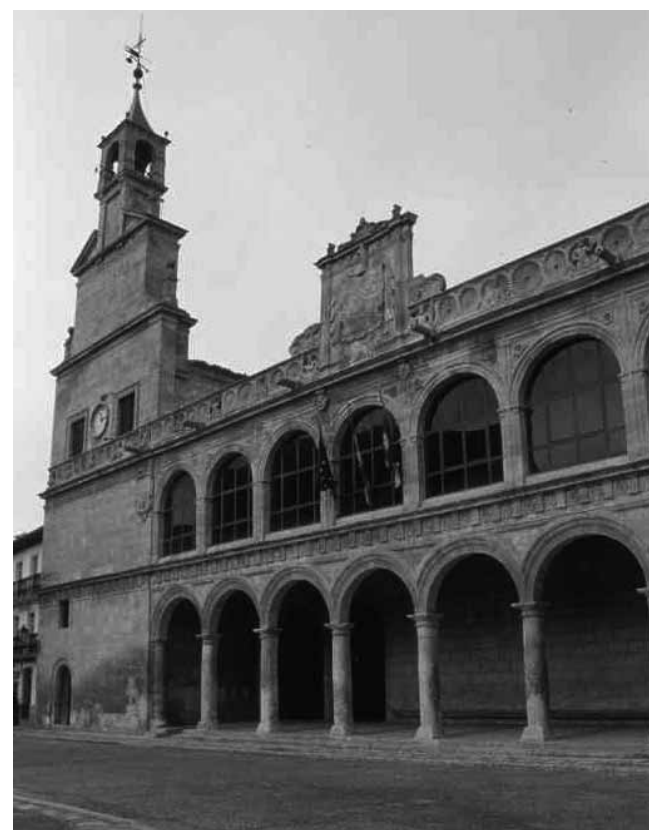

Fig. 2. Casas consistoriales, San Clemente (Cuenca), segundo tercio del siglo XVI, fachada.
Otro campo que también experimenta una profunda transformación con la llegada al trono de los Reyes Católicos fue el de la administración de justicia. En 1564, el jurista Bernardino de Sandoval advertía, en su Tractado del cvydado que se deve tener de los presos pobres, sobre la necesidad inherente a toda república y buen gobierno de juzgar y sentenciar, y por ende de disponer de las fábricas adecuadas para cumplir con tales cometidos ${ }^{8}$. Para la función de juzgar disponían los municipios de tribunales y salas de audiencia pública con sus gradas y estrados. En el interior de estas salas, el asiento del tribunal se alzaba habitualmente en uno de los costados menores. Estos sitiales, labrados en buena piedra de cantería o compuestos en madera, se elevaban sobre unas gradas a modo de tarima, resaltando en altura el asiento central, aquel que co-

6 DÍAZ DE MONTALVO, Alfonso, “Ordenanzas Reales de Castilla, por mandado de los muy altos, y muy poderosos, serenissimos, y catholicos principes, rey don Fernando, y reyna doña Isabel nuestros señores, recopiladas, y compuestas por el Doctor Alphonso Diaz de Montalvo, oydor de su audiencia, y su referendario, y de su consejo", en Los códigos españoles concordados y anotados, vol. VI, Madrid, Antonio de San Martín, 1872, p. 485.

De arquitectura [tratado del siglo XVI], Biblioteca Nacional, Madrid, Ms. 9681, edición de Cristina Gutiérrez-Cortines Corral, Madrid, Dirección General de Bellas Artes y Archivos, Consejo General de la Arquitectura Técnica de España, 1995, pp. 289-290.

8 SANDOUAL, Bernardino de, Tractado del cvydado que se deve tener de los presos pobres en que se trata ser obra pia proueer a las necessidades que padescen en las carceles, y que en muchas maneras pueden ser ayudados de sus proximos, y de las personas que tienen obligacion a fauorecerlos, y de otras cosas importantes en este proposito, Valencia, Librerías París-Valencia, 1997 (Toledo, 1614), f. 1v. 
rrespondía al corregidor u alcalde encargado de impartir justicia. Por otro lado, para la función de penar, los gobiernos municipales se servían de cárceles o prisiones. La preocupación, cada vez mayor entre los juristas y religiosos del Quinientos, por un mejor tratamiento de los presos y sus condiciones de reclusión, a la par que el auge que alcanzan entonces todos los criterios de salubridad e higiene pública, fueron razones suficientes para cuestionar la validez de muchos recintos carcelarios. Al tiempo que se censuraban malos usos en la administración de estas prisiones, se apuntaban soluciones para el emplazamiento y fábrica de estos edificios, para la organización y distribución de los espacios interiores, o para enumerar cuáles debían ser los aposentos necesarios en toda cárcel y de qué elementos debían estar dotados (fig. 3).

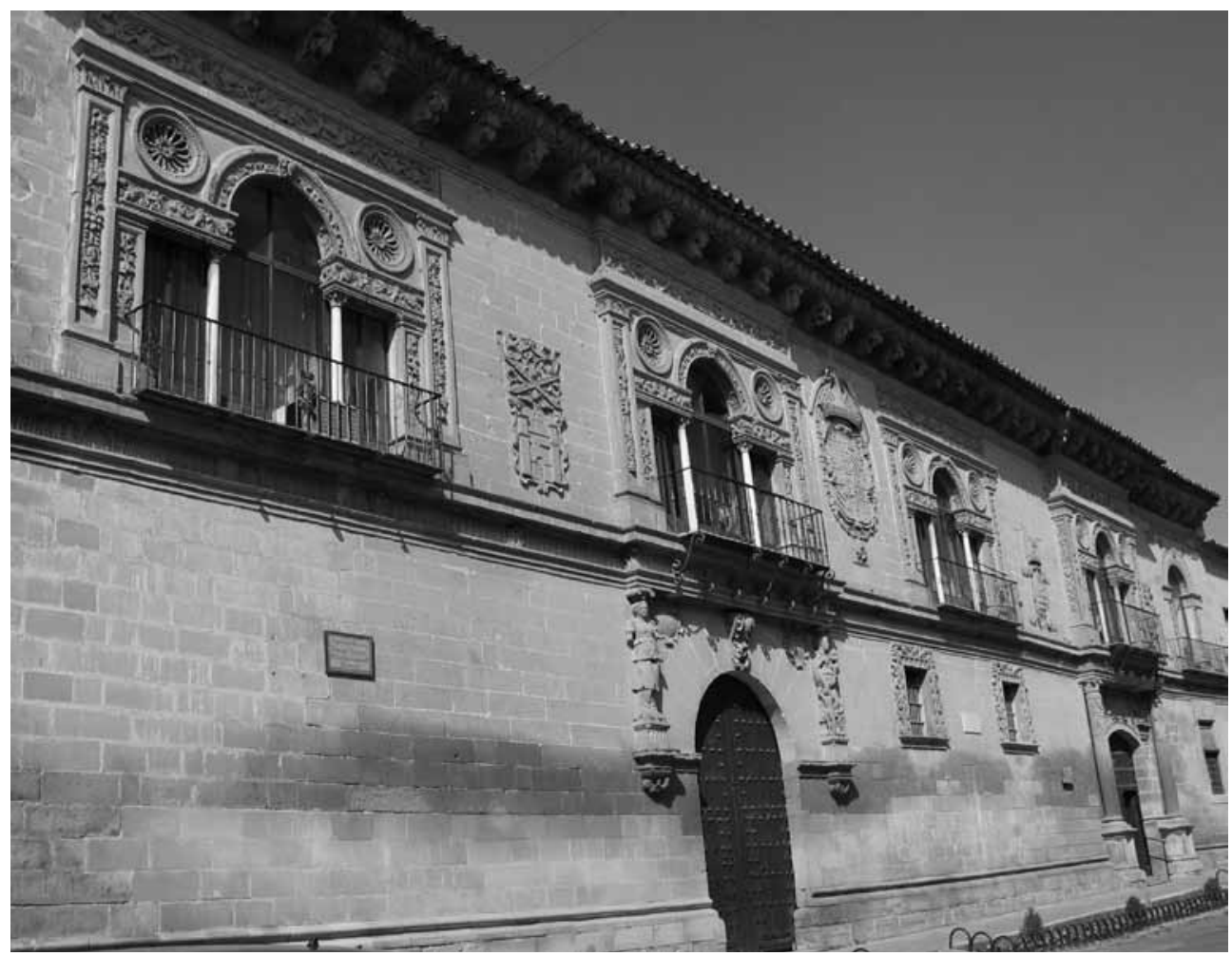

Fig. 3. Casa del corregidor y cárcel, Baeza (Jaén), segundo tercio del siglo XVI, fachada.

Con respecto a los mantenimientos, los concejos municipales detentan entonces la responsabilidad de garantizar el "orden y concierto" tanto en la adecuada provisión de las ciudades como en la venta pública. Tarea que conllevó no sólo la organización de los mercados, sino también la creación de una amplia red de abastecimiento público materializada en la ejecución de un completo programa 


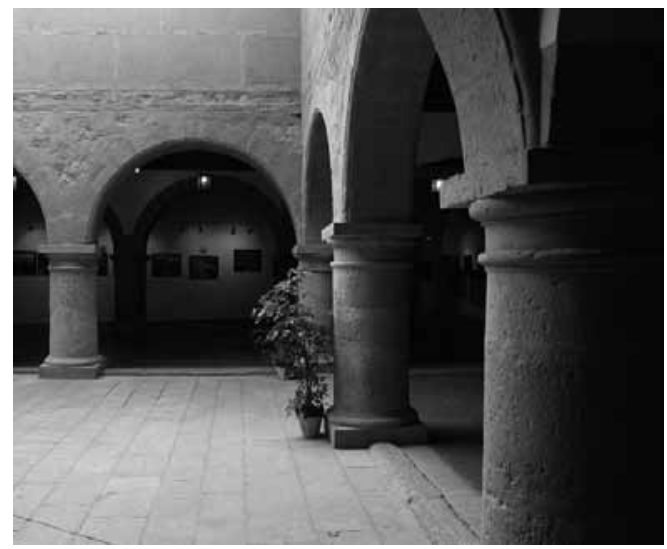

Fig. 4. Alhóndiga, Villanueva de los Infantes (Ciudad Real), segunda mitad del siglo XVI, patio interior. de equipamientos que abarcaba, entre otros, la construcción de casas de carnicería, redes del pescado, panaderías, rastros y mataderos. Nuevas edificaciones con las que los concejos pretendían ejercer un control más directo y periódico sobre los mantenimientos. De entre estos equipamientos, los pósitos y alhóndigas ocuparon siempre un lugar prioritario entre los programas de obras e infraestructuras públicas del siglo XVI, "siendo la entidad de esta oficina -como señalaba Juan Pedro Velázquez-Gaztelu- un manantial benéfico de las repúblicas florecientes, donde el labrador encuentra el recurso

necesario a sus urgencias y el vecino la seguridad de no faltarle el pan en los años calamitosos" (fig. 4) .

El abastecimiento de agua, por otro lado, fue también una de las preocupaciones más reiteradas para los concejos municipales del siglo XVI. La captación de los recursos acuíferos constituía el primer eslabón de todo un repertorio de fábricas hidráulicas que concluía con la erección de "lustrosas y hermosas fuentes", además de "albercas para los ganados y lavaderos de paños". La obra de fuentes y pilares representaba la feliz consecución de aquel arduo recorrido del agua y en su fábrica y emplazamiento urbano prevalecieron tanto la utilidad y funcionalidad de estos equipamientos, como el embellecimiento y ornato que proporcionaban a la ciudad, regenerando y cualificando aquellos espacios públicos donde se erigían (fig. 5). El resurgir de la fábrica de acueductos y la creación de otros "ingenios" hidráulicos que desafiaran los, a menudo, insalvables desniveles del terreno, ejemplifican también un extraordinario período de profundas transformaciones y avances tanto desde el punto de vista teórico como en la práctica de la ingeniería y arquitectura dedicada al abastecimiento hídrico.

Por último, una de las cuestiones que, en mayor medida, atrajo la atención de los concejos municipales del Quinientos fue la dejadez en materia de higiene y saneamiento que padecían las ciudades castellanas. Las graves carencias que, en este aspecto, aún presentaban municipios como Madrid o Valladolid a comienzos del XVII, fueron desafortunadamente una realidad extensible a toda la geografía castellana. Cuestiones como la ordenación y regularización del sistema viario, su

9 VELÁZQUEZ-GAZTELU, Juan Pedro, Historia antigua y moderna de Sanlúcar de Barrameda, Sanlúcar de Barrameda, Asociación Sanluqueña de Encuentros con la Historia y el Arte, 1992-1994, vol. II, p. 127. El Manuscrito original data de 1760. 


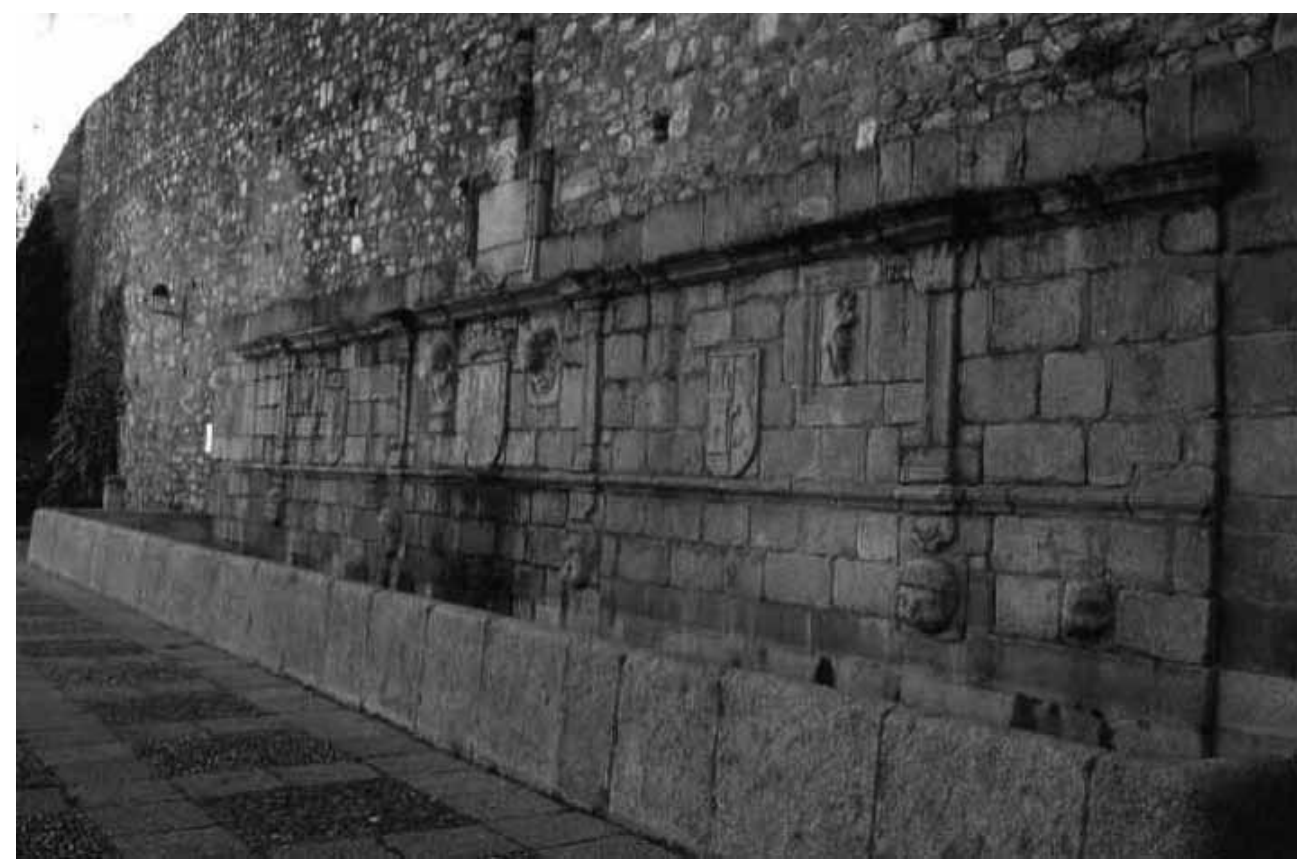

Fig. 5. Fuente de San Francisco, Cáceres, segunda mitad del siglo XVI, frente.

empedrado y mantenimiento, la supresión de saledizos y ajimeces, la canalización extramuros de las aguas sucias, la eliminación de inmundicias y lodazales, el alejamiento de los comercios insalubres, o la creación de muladares, recibieron una denodada atención por parte de los concejos, quienes se mostraron particularmente implicados en transformar la apariencia de las ciudades con el objetivo de, al menos, aproximarlas a aquella imagen un tanto idealizada que los laudes urbis transmitían de ellas.

Por otro lado, el legado de toda esta arquitectura de equipamientos y obras municipales cabe formularlo también en un contexto geográfico y temporal más amplio, del que toman parte todos aquellos territorios que integraban la Corona de Castilla en la Edad Moderna. Con similar funcionalidad, aquellas mismas tipologías de edificios que costeaban los concejos municipales peninsulares fueron empleadas en las nuevas ciudades que se iban fundando en los territorios de ultramar. Como ejemplo, baste citar que el cronista Diego Muñoz Camargo daba cuenta, en su extensa y precisa Descripción de la ciudad y provincia de Tlaxcala, del aspecto que ofrecía hacia 1585 la plaza mayor de aquel municipio novohispano y de los diversos equipamientos y obras públicas que albergaba, similares a los de cualquier gran núcleo urbano castellano del momento. Entre otros edificios, además de una "fuente de agua de extremada hechura" que adornaba el centro de la plaza, el mencionado cronista señalaba como allí se situaban "la cárcel pública de esta ciudad, [...] la casa de la morada de los alcaldes mayores y jueces que administran justicia, 
[...] donde está la Audiencia y tiene el juzgado el Alcalde Mayor muy curiosam[en] te adornado, [...] las carnicerías, [...] y otras casas muy principales de la ciudad, de mucho precio y valor y de maravillosa altura y grandeza, que exceden a las demás casas de que hemos tratado, [y] que, por su suntuosidad y majestad, las llaman las Casas Reales" ${ }^{\prime \prime}$. Casas consistoriales para acomodo de los cabildos municipales; puentes para facilitar el cruce de ríos; alhóndigas, pósitos, y carnicerías para la provisión de la población; o acueductos y fuentes para el abastecimiento hidráulico de las ciudades, integran en los territorios del Nuevo Mundo un inmenso repertorio de edificaciones y un sugerente campo de investigación, también conforme al tratamiento interdisciplinar previamente mencionado.

Concluimos haciendo hincapié en un argumento que nos ha suscitado el estudio de los equipamientos e infraestructuras municipales en territorio castellano. Entendemos que éste es un recorrido inacabado que, a nuestro juicio, requiere aún de nuevas investigaciones multidisciplinares, bien a modo de artículos o de monografías, que indaguen con mayor precisión en las fuentes documentales y en el conjunto de fábricas, infraestructuras y obras promovidas por los concejos de tantos y tantos municipios castellanos, aún pendientes de un estudio e interpretación exhaustiva. En este sentido, cabe recordar, la documentación municipal custodiada en archivos locales y provinciales supone aún una fuente inagotable e imprescindible para futuros investigadores.

${ }^{10}$ Relaciones geográficas del siglo XVI: Tlaxcala, México, Universidad Nacional Autónoma, 1984. Edición de René Acuña, vol. I, pp. 44-46. Correlato de esta descripción de la plaza Mayor de Tlaxcala es el plano de la misma, que acompaña el manuscrito conservado, en el que se muestra la disposición original de los singulares edificios y fábricas que albergaba este centro urbano (Cfr. MUÑOZ CAMARGO, Diego, Historia de Tlaxcala, f. 245r., sign Ms. Hunter 242 [U. 3. 15], Special Collections Hunterian Library, University of Glasgow, Escocia. Existe una edición facsímil a cargo de ACUÑA, René, Descripción de la ciudad y provincia de Tlaxcala de las Indias y del Mar Océano para el buen gobierno y entendimiento dellas, México, Universidad Nacional Autónoma de México, 1981). Cfr. también GUTIÉRREZ ARRIOLA, Cecilia, "La arquitectura de la ciudad de Tlaxcala en el siglo XVI (Notas sobre un dibujo de Muñoz Camargo)", en Historia y sociedad en Tlaxcala. Memorias del Cuarto y Quinto Simposios Internacionales de Investigaciones Socio-Históricas sobre Tlaxcala (Octubre de 1988, Octubre de 1989), México, Gobierno del Estado de Tlaxcala, Instituto Tlaxcalteca de Cultura, Universidad Autónoma de Tlaxcala, Universidad Iberoamericana, 1991, pp. 177-182. 